\title{
Higher frequency of dairy intake is associated with a reduced risk of breast cancer: Results from a case-control study in Northern and Eastern China
}

\author{
LIXIANG YU ${ }^{1,2}$, LIYUAN LIU ${ }^{1,2}$, FEI WANG ${ }^{1,2}$, FEI ZHOU ${ }^{1,2}$, YUJUAN XIANG ${ }^{1,2}$, SHUYA HUANG $^{1,2}$, \\ GENGSHEN YIN $^{1,2}$, YINGJIE ZHUO ${ }^{1,2}$, ZHONGBING MA ${ }^{1,2}$, QIANG ZHANG ${ }^{1,2}$ and ZHIGANG YU ${ }^{1-3}$ \\ ${ }^{1}$ Department of Breast Surgery, The Second Hospital of Shandong University; \\ ${ }^{2}$ Institute of Translational Medicine of Breast Disease Prevention and Treatment, Shandong University, Jinan, \\ Shandong 250033; ${ }^{3}$ Suzhou Institute, Shandong University, Suzhou, Jiangsu 215123, P.R. China
}

Received March 10, 2018; Accepted December 31, 2018

DOI: $10.3892 /$ ol.2019.9898

\begin{abstract}
The association between dairy intake and breast cancer risk has not been well investigated, especially in the Chinese population. This study aimed to examine the association between the weekly frequency of dairy intake and the risk of breast cancer among women in Northern and Eastern China, and to investigate whether the association varied by hormone receptor status. A total of 1,286 cases of breast cancer and 1,461 controls were enrolled in this study. Dairy intake was obtained using a food-frequency questionnaire (FFQ). Frequency of dairy intake per week was divided into four categories (<1 day/week, 1-2 days/week, 3-4 days/week and 5-7 days/week). Unconditional multivariate logistic regression analysis was used to estimate odds ratios (ORs) and 95\% confidence intervals (95\% CI). Stratified analyses were performed by residence, age, and education level. Separate analyses were also conducted for different estrogen receptor (ER) and progesterone receptor (PR) status. This analysis revealed that weekly frequency of dairy intake was strongly inversely associated with breast cancer risk, with an adjusted OR for intake 5-7 days/week of 0.53 (95\% CI=0.39-0.72, $\mathrm{P}<0.001$ for trend). In the stratified analyses, women who consumed dairy 5-7 days/week had a lower risk of breast cancer in urban areas $(\mathrm{OR}=0.45,95 \% \mathrm{CI}=0.30-0.66, \mathrm{P}<0.001$ for trend $)$, in the group 45-59 years old $(\mathrm{OR}=0.39,95 \% \mathrm{CI}=0.26-0.60, \mathrm{P}<0.001$ for trend), and in the group educated to senior high school or above $(\mathrm{OR}=0.39,95 \% \mathrm{CI}=0.25-0.59, \mathrm{P}<0.001$ for trend $)$. There was an inverse association between the weekly frequency of dairy intake and the risk of $\mathrm{ER}^{+}, \mathrm{PR}^{+}$, and $\mathrm{ER}^{+} \mathrm{PR}^{+}$breast
\end{abstract}

Correspondence to: Professor Zhigang Yu, Department of Breast Surgery, The Second Hospital of Shandong University, 247 Beiyuan Street, Tianqiao, Jinan, Shandong 250033, P.R. China

E-mail: yuzhigang@sdu.edu.cn

Key words: breast cancer risk, dairy intake, hormone receptor, case-control study China cancer (all $\mathrm{P}<0.001$ for trend). These results indicated that the weekly frequency of dairy intake was inversely associated with the risk of breast cancer among women in Northern and Eastern China.

\section{Introduction}

Worldwide, breast cancer is the most common cancer among women, with 1.67 million people diagnosed with breast cancer in 2012 (1). Although the incidence of breast cancer in China is historically low, it has been increasing twice as fast as that of the global rate in recent years (2-4). Breast cancer is a hormone-related malignancy; evidence suggests that hormone-related factors, such as obesity, parity, and the use of exogenous hormones, may affect the risk of breast cancer by increasing systemic exposure to hormones, which are modified by different hormone receptor status (5). Dairy may influence the risk of breast cancer through its effects on hormone levels (6), and it has been suggested that the correlation between dairy intake and the risk of breast cancer varies with hormone receptor status $(7,8)$.

With the rapid development of China's economy, the average intake of dairy products in China has gradually increased (9), and it is important to study the associations between dairy intake and breast cancer risk in Chinese women. Despite numerous studies evaluating the relationship between dairy intake and the risk of breast cancer in recent decades, the results have been non-conclusive (10-12). A previous pooling analysis from eight prospective cohort studies failed to detect significant associations between dairy intake and breast cancer risk (13); however, two recent meta-analyses suggested that compared with low dairy consumption, high dairy intake was associated with a reduced risk of breast cancer $(12,14)$. Dairy intake is likely to vary among different populations with varying geography, culture, socioeconomic status, and lifestyle habits. Nevertheless, most studies have been conducted in the United States or Northern Europe, with only two case-control studies reported in China (7,15). Therefore, the relationship between dairy intake and the risk of breast cancer in Chinese women requires further exploration. 
In order to better understand the characteristics and risk factors for breast cancer in Chinese women, a large case-control study including 21 hospitals in Northern and Eastern China was conducted between April 2012 and April 2013. Using data from a food-frequency questionnaire (FFQ), we aimed to find the relationship between the frequency of dairy intake and breast cancer risk in Chinese women, and whether the association varied by hormone receptor status was also investigated.

\section{Patients and methods}

Study population. The detailed study methods for this case-control study have been described in previous studies $(16,17)$. The target population was female outpatients with breast cancer aged 25-70 years from 21 hospitals in 11 provinces in Northern and Eastern China, from April 2012 to April 2013. Eligibility criteria for the case group were as follows: Newly diagnosed breast cancer (histologically confirmed), Han ethnic group, and females aged 25-70 years. Women who had recurrent or metastatic breast cancer and/or complications of other malignant tumors confirmed by clinical or pathological diagnosis were excluded from this group. The inclusion criteria for the control group were: Han ethnic group, having regular physical examinations or hospitalized at the same hospital with a similar visiting period ( \pm 2 months), being of 1:1 matched age with the cases ( \pm 3 years), negative physical examination results, negative ultrasound scans of breast and/or mammographic screening results, and no evidence or history of cancer. Patients who had neoplastic disease at any other site or other major chronic disease were excluded from the study.

Data collection. All participants completed face-to-face interviews based on a self-designed structured questionnaire after diagnosis, including basic demographic characteristics, reproductive factors, family history of breast cancer, and lifestyle habits, as described in a previous study (16). Dairy intake was obtained using a FFQ, which had also been used in a previous cross-sectional epidemiological survey (18). Participants were asked to recall their usual frequency of dairy intake per week in the 1-year period before diagnosis. The frequency of dairy intake per week was divided into four categories $(<1$ day/week, 1-2 days/week, 3-4 days/week, and 5-7 days/week). Medical and pathology records from the hospital where the patient was originally diagnosed were reviewed to obtain information on estrogen receptor (ER) and progesterone receptor (PR) status and other pathological results. Both ER and PR status were determined using immunohistochemical staining. Briefly, tissue specimens were sliced into $3-\mu \mathrm{m}$ sections. Then, sections were deparaffinized with xylene, rehydrated through a graded alcohol series. After antigen retrieval and blocking the endogenous peroxidase, the sections were stained with antibodies to ER (1:100 dilution; cat. no. Kit-0012) and PR (1:100 dilution; cat. no. Kit-0013) (both Maxim Biotech Inc., Fuzhou, China) according to the manufacturer's instructions. Following incubation, the secondary antibody horseradish peroxidase-conjugated goat anti-rabbit IgG (1:50 dilution; cat. no. A0208; Beyotime Institute of Biotechnology, Haimen, China) was added to the samples. Color reactions were visualized using 3,3'-diaminobenzidine. ER and PR expression was scored by two pathologists. Cell nuclei exhibiting brown staining were classified as positive cells. The proportion of stained cells for each tumor was recorded. Positivity was defined as $\geq 1 \%$ of tumor cells with positive staining, according to the American Society of Clinical Oncology (ASCO)/College of American Pathologists (2010) recommendations. All participating hospitals had national quality certifications for pathological diagnosis.

There were 1,489 case-control sets that met the inclusion criteria. After excluding participants with inadequate information (case group: 173 without hormone status information and 30 without dairy information; control group: 28 without dairy information), 1,286 cases and 1,461 controls were included in this study. All participants provided written informed consent and the study was approved by the Institutional Review Board at the Second Hospital of Shandong University.

Quality control. Interviewers were selected from medical professionals or medical post-graduates. All interviewer candidates were required to complete standardized training and were certified to conduct independent surveys. To minimize recall bias, several similar questions were asked in different sections of the questionnaire. The questionnaires and forms were coded twice and were double-entered by different clerks. Inconsistent records were manually checked and corrected. EpiData 3.1 software (EpiData Association, Odense, Denmark) to check the logic and reasonable range of responses throughout the questionnaire to identify contradictory responses was also used.

Statistical analysis. The percentage of variables was used to compare the distribution in each group, and significant differences in categorical variables were determined using the Chi-Square test. Unconditional multivariate logistic regression analysis was used to estimate the odds ratios (ORs) and $95 \%$ confidence intervals (95\% CIs) of dairy intake, using intake of $<1$ day/week as the reference. According to the literature, the following variables of breast cancer risk factors were included as covariates: Residence (urban, rural), age (25-44, 45-59, 60-70 years), education (junior high school or lower, senior high school or above), family monthly income $(<5,000, \geq 5,000 \mathrm{RMB})$, body mass index (BMI) $\left(<24.0, \geq 24.0 \mathrm{~kg} / \mathrm{m}^{2}\right)$, age of menarche $(\leq 12,13-14,15-16$, $\geq 17$ years), number of births $(0,1,2, \geq 3)$, age at first childbirth ( $<20,20-24,25-29,30-35, \geq 35$ years), breast-feeding (no, yes), menopausal status (premenopausal, postmenopausal), family history of breast cancer in first-degree relatives (no, yes), cigarette smoking (never, sometimes, often), alcohol drinking (never, sometimes, often), and physical activity (never, sometimes, often). Tests for trend were performed by treating the categorical variables as continuous variables in the models. Since the concept of healthy eating was likely to vary among populations with differing levels of urbanization, ages, and education, stratified analyses were performed by residence, age, and education level. Separate analyses were also conducted by different hormone receptor status $\left(\mathrm{ER}^{+}, \mathrm{ER}^{-}\right.$, $\mathrm{PR}^{+}, \mathrm{PR}^{-}, \mathrm{ER}^{+} \mathrm{PR}^{+}$, and $\mathrm{ER}^{-} \mathrm{PR}^{-}$), and the Wald test was used to evaluate heterogeneity across cancer subtypes. All data analyses were performed using SPSS software (version 16.0; SPSS Inc., Chicago, IL, USA). All statistical tests were two sided, and $\mathrm{P}<0.05$ was considered to indicate statistical significance. 
Table I. Characteristics of case and control groups.

\begin{tabular}{|c|c|c|c|c|}
\hline Variables & Control (\%) & Case $(\%)$ & $\chi^{2}$ & P-value \\
\hline Residence & & & 47.14 & $<0.001$ \\
\hline Rural & $510(37.14)$ & $617(50.53)$ & & \\
\hline Urban & $863(62.86)$ & $604(49.47)$ & & \\
\hline Age, years & & & 4.58 & 0.101 \\
\hline $25-44$ & $588(40.25)$ & $467(36.31)$ & & \\
\hline $45-59$ & $751(51.40)$ & $700(54.43)$ & & \\
\hline $60-70$ & $122(8.35)$ & $119(9.25)$ & & \\
\hline Education & & & 42.98 & $<0.001$ \\
\hline Junior high school or lower & $578(40.93)$ & $669(53.65)$ & & \\
\hline Senior high school or above & $834(59.07)$ & $578(46.35)$ & & \\
\hline Monthly family income, RMB & & & 28.03 & $<0.001$ \\
\hline$<5,000$ & $946(66.71)$ & $954(76.02)$ & & \\
\hline$\geq 5,000$ & $472(33.29)$ & $301(23.98)$ & & \\
\hline BMI & & & 1.59 & 0.207 \\
\hline$<24$ & $687(50.29)$ & $576(47.80)$ & & \\
\hline$\geq 24$ & $679(49.71)$ & $629(52.20)$ & & \\
\hline Age of menarche, years & & & 9.40 & 0.024 \\
\hline$\leq 12$ & $116(8.06)$ & $103(8.17)$ & & \\
\hline $13-14$ & $669(46.49)$ & $571(45.32)$ & & \\
\hline $15-16$ & $459(31.90)$ & $364(28.89)$ & & \\
\hline$\geq 17$ & $195(13.55)$ & $222(17.62)$ & & \\
\hline Number of births & & & 56.73 & $<0.001$ \\
\hline 0 & $40(2.78)$ & $27(2.13)$ & & \\
\hline 1 & $871(60.44)$ & $613(48.38)$ & & \\
\hline 2 & $419(29.08)$ & $439(34.65)$ & & \\
\hline$\geq 3$ & $111(7.70)$ & $188(14.84)$ & & \\
\hline Age at first childbirth, years ${ }^{a}$ & & & 4.13 & 0.389 \\
\hline$<20$ & $31(2.27)$ & $40(3.31)$ & & \\
\hline $20-24$ & $584(42.75)$ & $530(43.91)$ & & \\
\hline $25-29$ & $679(49.71)$ & $577(47.80)$ & & \\
\hline $30-35$ & $61(4.47)$ & $54(4.47)$ & & \\
\hline$\geq 35$ & $11(0.81)$ & $6(0.50)$ & & \\
\hline Breast-feeding & & & 0.67 & 0.412 \\
\hline No & $111(7.94)$ & $109(8.83)$ & & \\
\hline Yes & $1,287(92.06)$ & $1,126(91.17)$ & & \\
\hline Menopausal status & & & 8.61 & 0.003 \\
\hline Premenopausal & $988(70.42)$ & $813(65.09)$ & & \\
\hline Postmenopausal & $415(29.58)$ & $436(34.91)$ & & \\
\hline History of breast cancer in first-degree relatives & & & 3.25 & 0.072 \\
\hline No & $1,368(97.30)$ & $1,190(96.05)$ & & \\
\hline Yes & $38(2.70)$ & $49(3.95)$ & & \\
\hline Cigarette smoking & & & 5.91 & 0.052 \\
\hline Never & $1,427(97.87)$ & $1,238(96.42)$ & & \\
\hline Sometimes & $17(1.17)$ & $21(1.64)$ & & \\
\hline Often & $14(0.96)$ & $25(1.95)$ & & \\
\hline Alcohol drinking & & & 2.57 & 0.277 \\
\hline Never & $1,278(87.59)$ & $1,096(85.65)$ & & \\
\hline Sometimes & $169(11.58)$ & $171(13.35)$ & & \\
\hline Often & $12(0.82)$ & $14(1.09)$ & & \\
\hline
\end{tabular}


Table I. Continued.

\begin{tabular}{|c|c|c|c|c|}
\hline Variables & Control (\%) & Case $(\%)$ & $\chi^{2}$ & P-value \\
\hline Physical activity & & & 5.59 & 0.061 \\
\hline Never & $410(28.20)$ & $364(28.44)$ & & \\
\hline Sometimes & $663(45.60)$ & $534(41.72)$ & & \\
\hline Often & $381(26.20)$ & $382(29.84)$ & & \\
\hline Hormone receptor status & & & - & - \\
\hline $\mathrm{ER}^{+}$ & - & $977(75.97)$ & & \\
\hline $\mathrm{ER}^{-}$ & - & $309(24.03)$ & & \\
\hline $\mathrm{PR}^{+}$ & - & $888(69.05)$ & & \\
\hline $\mathrm{PR}^{-}$ & - & $398(30.95)$ & & \\
\hline $\mathrm{ER}^{+} \mathrm{PR}^{+}$ & - & $868(67.50)$ & & \\
\hline ER-PR- & - & $289(22.47)$ & & \\
\hline
\end{tabular}

alimited to participants who had children. BMI, body mass index; ER, estrogen receptor; PR, progesterone receptor.

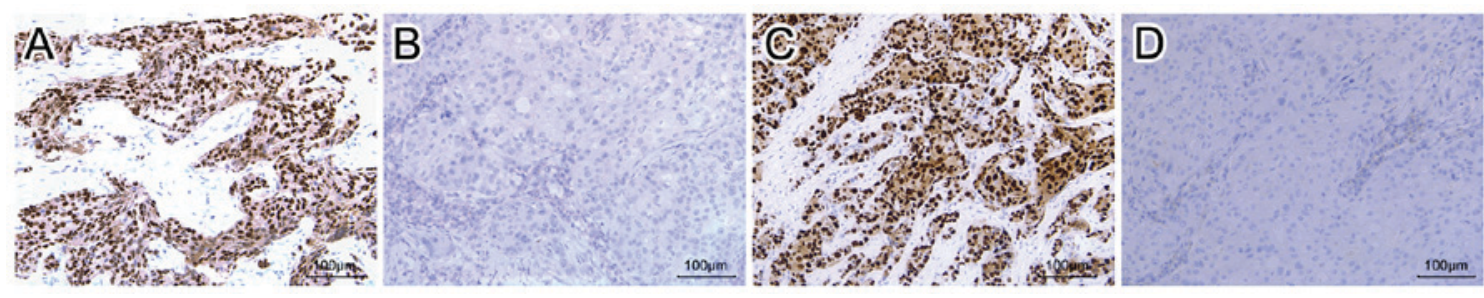

Figure 1. Schematic representation of the expression of ER and PR in breast cancer tissues by immunohistochemical staining (magnification, x200). Cells exhibiting brown staining were classified as positive cells. The positive cells were counted and the positive rate was calculated. Positive expression of ER and PR was defined as $\geq 1 \%$ of tumor cells with positive staining, and negative expression was defined as $<1 \%$ of tumor cells with positive staining. (A) ER ${ }^{+}$, (B) ER , (C) $\mathrm{PR}^{+}$and (D) $\mathrm{PR}$. ER, estrogen receptor; $\mathrm{PR}$, progesterone receptor.

\section{Results}

Overall descriptive characteristics. A total of 1,286 cases of breast cancer and 1,461 controls were enrolled in this study. Among 1,286 cases of breast cancer, 977 (75.97\%) cases were $\mathrm{ER}^{+}$breast cancer, $888(69.05 \%)$ cases were $\mathrm{PR}^{+}, 868(67.50 \%)$ cases were $\mathrm{ER}^{+} \mathrm{PR}^{+}$, and $289(22.47 \%)$ cases were ER-PRSince there was limited data for $\mathrm{ER}^{+} \mathrm{PR}^{-}$(109 cases, 8.48\%) and $\mathrm{ER}^{-} \mathrm{PR}^{+}(20$ cases, $1.56 \%)$ breast cancer, no further analysis was conducted. The schematic representation of positive or negative expression of ER and PR by immunohistochemical staining is presented in Fig. 1. Basic demographic information of the case and control groups is presented in Table I. In this analysis, there was no significant difference in age, BMI, age at first childbirth, breast-feeding, family history of breast cancer in first-degree relatives, cigarette smoking, alcohol drinking, and physical activity between case and control groups (all $\mathrm{P}>0.05$ ). The case group had a higher proportion of participants from a rural population, and also had lower education levels and family income (all $\mathrm{P}<0.001$ ). The data also indicated that the case group had an earlier age of menarche, greater number of births, and a higher proportion of postmenopausal participants (all $\mathrm{P}<0.05)$ (Table I).

Weekly frequency of dairy intake and risk of breast cancer in different subgroups. The relationships between the weekly frequency of dairy intake and the risk of breast cancer combined in different subgroups are presented in Table II. The weekly frequency of dairy intake was significantly and inversely associated with breast cancer risk. Compared with women who consumed dairy $<1$ day/week, women who consumed dairy 3-4 days/week had a 31\% reduction in breast cancer $(\mathrm{OR}=0.69,95 \% \mathrm{CI}=0.53-0.90)$, and those who consumed dairy 5-7 days/week had a $47 \%$ reduction in breast cancer $(\mathrm{OR}=0.53,95 \% \mathrm{CI}=0.39-0.72, \mathrm{P}<0.001$ for trend). In the stratified analyses, women who consumed dairy 5-7 days/week had a lower risk of breast cancer in urban areas $(\mathrm{OR}=0.45,95 \% \mathrm{CI}=0.30-0.66, \mathrm{P}<0.001$ for trend), in the group 45-59 years old $(\mathrm{OR}=0.39,95 \% \mathrm{CI}=0.26-0.60, \mathrm{P}<0.001$ for trend) and in the group with a senior high school education or above $(\mathrm{OR}=0.39,95 \% \mathrm{CI}=0.25-0.59, \mathrm{P}<0.001$ for trend). No significant associations were found for weekly frequency of dairy intake and breast cancer risk for those in rural areas, those aged 60-70 years old, and in those with a junior high school education or lower (all P>0.05 for trend; Table II).

Weekly frequency of dairy intake and risk of breast cancer in different hormone receptor status cases. When stratified by different hormone receptor subtypes $\left(\mathrm{ER}^{+}, \mathrm{ER}^{-}, \mathrm{PR}^{+}\right.$, $\mathrm{PR}^{-}, \mathrm{ER}^{+} \mathrm{PR}^{+}$, and $\left.\mathrm{ER}^{-} \mathrm{PR}^{-}\right)$, there was an inverse association between the weekly frequency of dairy intake and the risk of $\mathrm{ER}^{+}, \mathrm{PR}^{+}$, and $\mathrm{ER}^{+} \mathrm{PR}^{+}$breast cancer (all $\mathrm{P}<0.001$ for trend). 
Table II. Frequency of dairy intake and risk of breast cancer in different subgroups.

\begin{tabular}{|c|c|c|c|c|c|}
\hline \multirow[b]{2}{*}{ Subjects } & \multicolumn{4}{|c|}{ Dairy intake, days/week } & \multirow[b]{2}{*}{ Trend P-value } \\
\hline & $<1$ & $1-2$ & $3-4$ & $5-7$ & \\
\hline \multicolumn{6}{|l|}{ Total } \\
\hline Controls & 332 & 432 & 405 & 292 & \\
\hline Cases & 391 & 434 & 296 & 165 & \\
\hline OR $(95 \% \mathrm{CI})^{\mathrm{a}}$ & $1^{\mathrm{b}}$ & $0.91(0.72-1.16)$ & $0.69(0.53-0.90)$ & $0.53(0.39-0.72)$ & $<0.001$ \\
\hline \multicolumn{6}{|l|}{ Residence } \\
\hline \multicolumn{6}{|l|}{ Rural } \\
\hline Cases & 223 & 225 & 121 & 48 & \\
\hline OR $(95 \% \mathrm{CI})^{\mathrm{a}}$ & $1^{\mathrm{b}}$ & $1.13(0.81-1.59)$ & $0.86(0.58-1.28)$ & $0.67(0.39-1.16)$ & 0.138 \\
\hline \multicolumn{6}{|l|}{ Urban } \\
\hline Cases & 151 & 189 & 157 & 107 & \\
\hline OR $(95 \% \mathrm{CI})^{\mathrm{a}}$ & $1^{\mathrm{b}}$ & $0.74(0.52-1.06)$ & $0.56(0.39-0.81)$ & $0.45(0.30-0.66)$ & $<0.001$ \\
\hline \multicolumn{6}{|l|}{ Age, years } \\
\hline \multicolumn{6}{|l|}{$25-44$} \\
\hline Cases & 133 & 166 & 113 & 55 & \\
\hline OR $(95 \% \mathrm{CI})^{\mathrm{a}}$ & $1^{\mathrm{b}}$ & $1.03(0.69-1.53)$ & $0.73(0.48-1.12)$ & $0.66(0.40-1.10)$ & 0.043 \\
\hline \multicolumn{6}{|l|}{$45-59$} \\
\hline Cases & 229 & 226 & 153 & 92 & \\
\hline OR $(95 \% \mathrm{CI})^{\mathrm{a}}$ & $1^{\mathrm{b}}$ & $0.82(0.59-1.13)$ & $0.67(0.46-0.97)$ & $0.39(0.26-0.60)$ & $<0.001$ \\
\hline \multicolumn{6}{|l|}{$60-70$} \\
\hline Cases & 29 & 42 & 30 & 18 & \\
\hline OR $(95 \% \mathrm{CI})^{\mathrm{a}}$ & $1^{\mathrm{b}}$ & $1.27(0.47-3.43)$ & $0.89(0.31-2.50)$ & $1.12(0.32-3.89)$ & 0.900 \\
\hline \multicolumn{6}{|l|}{ Education } \\
\hline \multicolumn{6}{|c|}{ Junior high school or lower } \\
\hline Cases & 260 & 230 & 127 & 52 & \\
\hline OR $(95 \% \mathrm{CI})^{\mathrm{a}}$ & $1^{\mathrm{b}}$ & $1.07(0.78-1.47)$ & $0.83(0.57-1.20)$ & $0.69(0.43-1.13)$ & 0.106 \\
\hline \multicolumn{6}{|c|}{ Senior high school or above } \\
\hline Cases & 124 & 195 & 154 & 105 & \\
\hline OR $(95 \% \mathrm{CI})^{\mathrm{a}}$ & $1^{\mathrm{b}}$ & $0.70(0.48-1.03)$ & $0.51(0.34-0.76)$ & $0.39(0.25-0.59)$ & $<0.001$ \\
\hline
\end{tabular}

No significant associations were found between weekly dairy intake and the risk of $\mathrm{ER}^{-}, \mathrm{PR}^{-}$, and $\mathrm{ER}^{-} \mathrm{PR}^{-}$breast cancer (all $\mathrm{P}>0.05$ for trend). In addition, no statistically significant heterogeneity was found in the risk estimates for the frequency of dairy intake between the different hormone receptor subtypes (all P>0.05 for heterogeneity; Table III).

\section{Discussion}

In the present case-control study, the weekly frequency of dairy intake had a strong inverse association with the risk of breast cancer overall, especially among women in urban areas, women with a senior high school education or above, and women aged 45-59 years old in Northern and Eastern
China. When analyses were performed by different hormone receptor status, significantly inverse associations were found between the weekly frequency of dairy intake and the risk of hormone receptor-positive $\left(\mathrm{ER}^{+}, \mathrm{PR}^{+}\right.$, and $\left.\mathrm{ER}^{+} \mathrm{PR}^{+}\right)$breast cancer, but not for hormone receptor-negative breast cancer. However, this conclusion should be considered with caution. It is important to take into account that there were fewer documented receptor-negative breast cancers, and that the Wald test revealed no detected differences between positive and negative receptor breast cancers.

Dairy intake has been thought to be associated with the development of breast cancer (19), yet, to date, epidemiological evidence is inconsistent. Several large epidemiologic studies have failed to demonstrate a relationship between dairy intake 
Table III. Frequency of dairy intake and risk of breast cancer in different hormone receptor status cases.

\begin{tabular}{|c|c|c|c|c|c|c|}
\hline \multirow[b]{2}{*}{ Subjects } & \multicolumn{4}{|c|}{ Dairy intake, days/week } & \multirow{2}{*}{$\begin{array}{l}\text { Trend } \\
\text { P-value }\end{array}$} & \multirow{2}{*}{$\begin{array}{l}\text { Heterogeneity } \\
\text { P-value }\end{array}$} \\
\hline & $<1$ & $1-2$ & $3-4$ & $5-7$ & & \\
\hline Controls & 332 & 432 & 405 & 292 & & \\
\hline \multicolumn{7}{|l|}{$\mathrm{ER}^{+}$} \\
\hline Cases & 313 & 311 & 225 & 128 & & \\
\hline $\mathrm{OR}(95 \% \mathrm{CI})^{\mathrm{b}}$ & $1^{\mathrm{c}}$ & $0.83(0.64-1.07)$ & $0.66(0.50-0.87)$ & $0.51(0.36-0.70)$ & $<0.001$ & 0.158 \\
\hline \multicolumn{7}{|l|}{$\mathrm{ER}^{-}$} \\
\hline Cases & 78 & 123 & 71 & 37 & & \\
\hline OR $(95 \% \mathrm{CI})^{\mathrm{b}}$ & $1^{\mathrm{c}}$ & $1.37(0.92-2.05)$ & $0.870(0.55-1.38)$ & $0.68(0.40-1.15)$ & 0.052 & \\
\hline \multicolumn{7}{|l|}{$\mathrm{PR}^{+}$} \\
\hline Cases & 278 & 290 & 204 & 116 & & \\
\hline $\mathrm{OR}(95 \% \mathrm{CI})^{\mathrm{b}}$ & $1^{\mathrm{c}}$ & $0.84(0.64-1.09)$ & $0.64(0.48-0.85)$ & $0.49(0.35-0.68)$ & $<0.001$ & 0.412 \\
\hline \multicolumn{7}{|l|}{$\mathrm{PR}^{-}$} \\
\hline Cases & 113 & 144 & 92 & 49 & & \\
\hline OR $(95 \% \mathrm{CI})^{\mathrm{b}}$ & $1^{\mathrm{c}}$ & $1.18(0.82-1.69)$ & $0.88(0.58-1.32)$ & $0.69(0.43-1.11)$ & 0.066 & \\
\hline \multicolumn{7}{|l|}{$\mathrm{ER}^{+} \mathrm{PR}^{+}$} \\
\hline Cases & 275 & 282 & 196 & 115 & & \\
\hline OR $(95 \% \mathrm{CI})^{\mathrm{b}}$ & $1^{\mathrm{c}}$ & $0.83(0.64-1.07)$ & $0.62(0.46-0.82)$ & $0.49(0.35-0.69)$ & $<0.001$ & 0.220 \\
\hline \multicolumn{7}{|l|}{ ER-PR- } \\
\hline Cases & 75 & 115 & 63 & 36 & & \\
\hline OR $(95 \% \mathrm{CI})^{\mathrm{b}}$ & $1^{\mathrm{c}}$ & $1.33(0.89-2.01)$ & $0.78(0.48-1.27)$ & $0.71(0.41-1.22)$ & 0.060 & \\
\hline
\end{tabular}

and breast cancer $(10,12)$. However, a recent meta-analysis conducted by Zang et al (12), including 22 prospective cohort studies $(1,566,940$ participants) and five case-control studies (33,372 participants), revealed that high and modest dairy intake significantly reduced the risk of breast cancer compared with low dairy consumption. To date, these studies, especially the cohort studies, have mainly been conducted in Western countries. A meta-analysis of five case-control studies from Asia indicated that higher dairy or milk intake was associated with a $27 \%$ reduction in breast cancer risk, but only two studies were performed in the Chinese population (8). In the present study, dairy intake was associated with a reduced risk of breast cancer among women in Northern and Eastern China. Dairy foods are rich in vitamin D and calcium, and have been hypothesized to have an anti-carcinogenic effect on cell differentiation, proliferation, and anti-apoptosis $(19,20)$. In the present study, a significant relationship was revealed between dairy intake and the risk of breast cancer among women in urban areas and with an education level of senior high school or above, but not in rural areas and those with a lower education level. This was likely because the concept of healthy eating is associated with urbanization and education levels, and high-quality diets are more often consumed by urban and better educated people $(21,22)$; these diets include foods such as yogurt, and have had a better effect on breast cancer prevention (23). It was observed that dairy intake was a significant protective factor for breast cancer among women aged 45-59 years old. Research has revealed that the peak of incidence rate of breast cancer in Chinese women is in the group aged 45-59 years (2). The frequency of dairy intake in this group was not more than other groups in the present study and some studies have revealed that this group had the lowest frequency of dairy intake among the Chinese population (9). This was an interesting finding and may indicate that dairy may have a stronger protective effect among women aged 45-59 years old in China. If confirmed, this could have important implications for breast cancer prevention strategies.

To the best of our knowledge, a limited number of studies have shown the potential relationship between dairy intake and breast cancer by different hormone receptor status. In the Malmo Diet and Cancer cohort, regular milk and yogurt were associated with protective linear risk trends for $\mathrm{ER}^{+} \mathrm{PR}^{+}$breast cancer (23). A population-based case-control study (The Shanghai Breast Cancer Study) conducted by Bao et al (7) revealed that milk intake was associated with a reduced risk of $\mathrm{ER}^{+} \mathrm{PR}^{+}$breast cancer, which was similar to the present 
findings. However, a cohort study of African-American women found null associations for dairy intake and risk of $\mathrm{ER}^{+} \mathrm{PR}^{+}$ breast cancer (11). It had been thought that the risk factors associated with hormone-receptor positive breast cancer mainly involved hormonal mechanisms related to estrogen and progesterone exposure, and Wirfalt et al (23) hypothesized that the protective association between fermented milk and $\mathrm{ER}^{+} \mathrm{PR}^{+}$breast cancer possibly implies a hormone-dependent mechanism involving fiber and enterolactone. Enterolactone, a phytoestrogen formed in the gut, could modulate the activity of estrogen receptors and decrease estrogen exposure (24), and lactic acid bacteria from dairy products were involved in stabilizing the gut environment by suppressing pathological bacteria and lowering the $\mathrm{pH}$ in the gut, which was important for the production of enterolactone (25). However, the exact mechanism requires more investigation.

There are some limitations in the present study that need to be addressed. First, potential recall bias is one major limitation of this case-control study. The diet of participants from the previous year was used as the surrogate for overall exposure. Second, in this study the data of a previous case-control study was reanalyzed (16). The frequency of dairy intake per week was collected using a questionnaire that considered dietary exposure in the one-year period before the survey, but the dairy subtype and amount consumed were not assessed. Therefore, the association between the amount consumed or different dairy items (e.g., whole milk, low fat milk, yogurt) and breast cancer risk could not be analyzed. It is also important to explore the interaction between dairy intake and protein or lipid intake in breast cancer. However, protein and lipid intake were not collected in this study; thus, the interaction between dairy intake and protein or lipid intake in breast cancer could not be analyzed. Third, the small sample size was also one of the limitations in this study. A breast cancer cohort in China is currently being established by the authors, and the number of samples will be expanded in future research. Finally, significant inverse associations between the weekly frequency of dairy intake and the risk of hormone receptor-positive $\left(\mathrm{ER}^{+}, \mathrm{PR}^{+}\right.$, and $\left.\mathrm{ER}^{+} \mathrm{PR}^{+}\right)$breast cancer was revealed, but not in hormone receptor-negative breast cancer. However, this conclusion should be considered with caution. It is important to take into account that there were fewer receptor-negative breast cancers, and that no differences were detected using the Wald test between positive and negative receptor breast cancers. In the future, we aim to validate the protective effect of dairy intake in this study using a better-designed study.

In summary, it was observed that the weekly frequency of dairy intake was strongly inversely associated with breast cancer risk among women in Northern and Eastern China. Separate analyses by different hormone receptor status revealed that dairy intake was a protective factor for hormone receptor-positive $\left(\mathrm{ER}^{+}, \mathrm{PR}^{+}\right.$, and $\left.\mathrm{ER}^{+} \mathrm{PR}^{+}\right)$breast cancer. However, this conclusion should be considered with caution. The impact of dairy products on breast cancer risk may involve multiple factors, and different dietary components may also interact in the development of breast cancer. Future well-designed epidemiological studies, especially large cohort studies of Chinese women, are required to clarify the relevance of dairy intake to breast cancer risk.

\section{Acknowledgements}

The authors would like to thank Dr Jie Li, School of Nursing, Shandong University, China, for her help.

\section{Funding}

The present study was supported by the Key Project of the Natural Science Foundation of Shandong Province, China (ZR2014HZ004), the Natural Science Foundation of Shandong Province, China (ZR2014HL074) and the Science and Technology Plan Projects of Jiangsu Province (BL2014055).

\section{Availability of data and materials}

The datasets used and/or analyzed during the current study are available from the corresponding author on reasonable request.

\section{Authors' contributions}

LY participated in the study design, population survey, and data interpretation, and drafted the manuscript. LL and FW supervised the study and analyzed the data. FZ, YX, SH, GY, YZ, ZM and QZ participated in the population survey and data collection. ZY was the chief designer of this study and wrote the final draft. All authors read and approved the manuscript and agree to be accountable for all aspects of the research in ensuring that the accuracy or integrity of any part of the work are appropriately investigated and resolved.

\section{Ethics approval and consent to participate}

All participants provided written informed consent and the study was approved by the Institutional Review Board at the Second Hospital of Shandong University.

\section{Patient consent for publication}

Not applicable.

\section{Competing interests}

The authors declare that they have no competing interests.

\section{References}

1. Torre LA, Bray F, Siegel RL, Ferlay J, Lortet-Tieulent J and Jemal A: Global cancer statistics, 2012. CA Cancer J Clin 65: 87-108, 2015.

2. Chen W, Zheng R, Baade PD, Zhang S, Zeng H, Bray F, Jemal A, Yu XQ and He J: Cancer statistics in China, 2015. CA Cancer J Clin 66: 115-132, 2016.

3. Fan L, Strasser-Weippl K, Li JJ, St LJ, Finkelstein DM, Yu KD, Chen WQ, Shao ZM and Goss PE: Breast cancer in China. Lancet Oncol 15: e279-e289, 2014.

4. Fan L, Zheng Y, Yu KD, Liu GY, Wu J, Lu JS, Shen KW, Shen ZZ and Shao ZM: Breast cancer in a transitional society over 18 years: Trends and present status in Shanghai, China. Breast Cancer Res Treat 117: 409-416, 2009.

5. Althuis MD, Fergenbaum JH, Garcia-Closas M, Brinton LA, Madigan MP and Sherman ME: Etiology of hormone receptor-defined breast cancer: A systematic review of the literature. Cancer Epidemiol Biomarkers Prev 13: 1558-1568, 2004. 
6. Outwater JL, Nicholson A and Barnard N: Dairy products and breast cancer: The IGF-I, estrogen, and bGH hypothesis. Med Hypotheses 48: 453-461, 1997.

7. Bao PP, Shu XO, Zheng Y, Cai H, Ruan ZX, Gu K, Su Y, Gao YT, Zheng W and Lu W: Fruit, vegetable, and animal food intake and breast cancer risk by hormone receptor status. Nutr Cancer 64: 806-819, 2012.

8. Lof $\mathrm{M}$ and Weiderpass E: Impact of diet on breast cancer risk. Curr Opin Obstet Gynecol 21: 80-85, 2009.

9. He Y, Yang X, Xia J, Zhao L and Yang Y: Consumption of meat and dairy products in China: A review. Proc Nutr Soc 75: 385-391, 2016.

10. Pala V, Krogh V, Berrino F, Sieri S, Grioni S, Tjønneland A, Olsen A, Jakobsen MU, Overvad K, Clavel-Chapelon F, et al: Meat, eggs, dairy products, and risk of breast cancer in the European Prospective Investigation into Cancer and Nutrition (EPIC) cohort. Am J Clin Nutr 90: 602-612, 2009.

11. Genkinger JM, Makambi KH, Palmer JR, Rosenberg L and Adams-Campbell LL: Consumption of dairy and meat in relation to breast cancer risk in the Black Women's Health Study. Cancer Causes Control 24: 675-684, 2013.

12. Zang J, Shen M, Du S, Chen T and Zou S: The association between dairy intake and breast cancer in western and asian populations: A systematic review and meta-analysis. J Breast Cancer 18: 313-322, 2015.

13. Missmer SA, Smith-Warner SA, Spiegelman D, Yaun SS, Adami HO, Beeson WL, van den Brandt PA, Fraser GE, Freudenheim JL, Goldbohm RA, et al: Meat and dairy food consumption and breast cancer: A pooled analysis of cohort studies. Int J Epidemiol 31: 78-85, 2002.

14. Dong JY, Zhang L, He K and Qin LQ: Dairy consumption and risk of breast cancer: A meta-analysis of prospective cohort studies. Breast Cancer Res Treat 127: 23-31, 2011.

15. Zhang CX, Ho SC, Fu JH, Cheng SZ, Chen YM and Lin FY: Dairy products, calcium intake, and breast cancer risk: A case-control study in China. Nutr Cancer 63: 12-20, 2011.

16. Liu LY, Wang F, Cui SD, Tian FG, Fan ZM, Geng CZ, Cao XC, Yang ZL, Wang X, Liang $\mathrm{H}$, et al: A case-control study on risk factors of breast cancer in Han Chinese women. Oncotarget 8: 97217-97230, 2017.
17. Liu LY, Wang YJ, Wang F, Yu LX, Xiang YJ, Zhou F, Li L, Zhang Q, Fu QY, Ma ZB, et al: Factors associated with insufficient awareness of breast cancer among women in Northern and Eastern China: A case-control study. BMJ Open 8: e018523, 2018.

18. Yu ZG, Jia CX, Liu LY, Geng CZ, Tang JH, Zhang J, Zhang Q, Li YY and Ma ZB: The prevalence and correlates of breast cancer among women in Eastern China. PLoS One 7: e37784, 2012

19. Thorning TK, Raben A, Tholstrup T, Soedamah-Muthu SS, Givens I and Astrup A: Milk and dairy products: Good or bad for human health? An assessment of the totality of scientific evidence. Food Nutr Res 60: 32527, 2016.

20. Lipkin M and Newmark HL: Vitamin D, calcium and prevention of breast cancer: A review. J Am Coll Nutr 18 (Suppl 5): S392-S397, 1999.

21. Darmon N and Drewnowski A: Does social class predict diet quality. Am J Clin Nutr 87: 1107-1117, 2008.

22. Yuan YQ, Li F, Dong RH, Chen JS, He GS, Li SG and Chen B: The development of a chinese healthy eating index and its application in the general population. Nutrients 9: E977, 2017.

23. Wirfält E, Li C, Manjer J, Ericson U, Sonestedt E, Borgquist S, Landberg G, Olsson $\mathrm{H}$ and Gullberg B: Food sources of fat and sex hormone receptor status of invasive breast tumors in women of the Malmö Diet and Cancer cohort. Nutr Cancer 63: 722-733, 2011.

24. Sonestedt E, Borgquist S, Ericson U, Gullberg B, Olsson H, Adlercreutz H, Landberg $\mathrm{G}$ and Wirfält E: Enterolactone is differently associated with estrogen receptor beta-negative and-positive breast cancer in a Swedish nested case-control study. Cancer Epidemiol Biomarkers Prev 17: 3241-3251, 2008.

25. de Moreno de LeBlanc A, Matar C and Perdigón G: The application of probiotics in cancer. Br J Nutr 98 (Suppl 1): S105-S110, 2007.

cc) (i) $\ominus$ This work is licensed under a Creative Commons

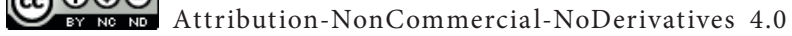
International (CC BY-NC-ND 4.0) License. 